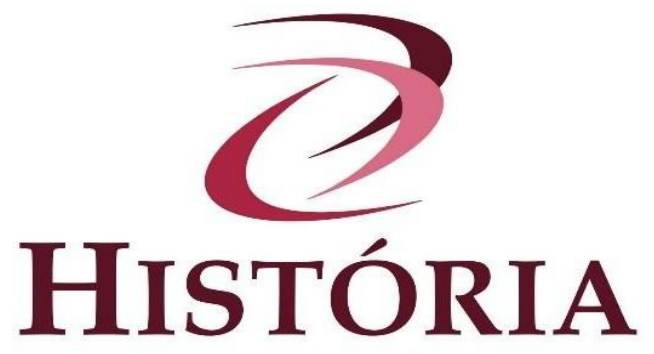

\title{
O narrador sensível ${ }^{i}$ \\ The Tender Narrator \\ Czuly narrator
}

\author{
Olga Tokarczuk ${ }^{\mathrm{ii}}$ \\ Tradução: Alcione Nawroski ${ }^{i i i}$
}

1.

A primeira fotografia da qual eu tenho conhecimento é uma foto da minha mãe antes de eu nascer. Infelizmente é uma foto em preto e branco, por isso muitos detalhes ficaram desaparecidos, convertendo-se em formas acinzentadas. A luz é suave e úmida, possivelmente uma luz de primavera que atravessava as frestas de uma janela mantendo a sala com um brilho perceptível. Minha mãe esta sentada ao lado de um rádio velho, como esses que tem um olho verde e dois botões, um para controlar o volume e outro para localizar as estações. Esse rádio, logo, se converteu em meu grande companheiro de infância, donde aprendi sobre a existência dos cosmos. Ao girar o botão, as delicadas ondas sonoras das antenas se moviam e alcançavam as estações dos mais diferentes lugares: Varsóvia, Londres, Luxemburgo e Paris. Às vezes, entretanto, alguma estação falhava como entre Praga e Nova York, Moscou e Madri como se as ondas sonoras passassem por alguns buracos negros. E então dava um frio na espinha. Eu acreditava que diferentes sistemas solares e galáxias conversavam comigo através destas rádios, as quais por meio de crepitações e chiados me enviavam informações, as quais eu não sabia decifrar.

Quando menina, ao olhar para essa foto, acreditava que minha mãe me procurava girando o botão do rádio. Como um radar sensível, penetrava nos reinados infinitos dos cosmos tentando descobrir quando e de onde eu viria. O corte de cabelo e sua vestimenta (com um decote grande) denunciam a época em que a foto foi tirada, no início dos anos sessenta. Ao olhar a foto fora de ângulo, percebemos que a mulher encurvada eleva seu olhar para algo que não está visível, coisas que só percebemos quando nos concentramos 
na fotografia. Quando eu era criança, imaginava que ela olhava para o tempo. Na foto nada acontece, é o enquadramento de um estado e não de um processo. A mulher está triste, aparentemente perdida em seus pensamentos.

Mais tarde, quando eu perguntei sobre essa tristeza, e fiz isso muitas vezes, sempre escutei a mesma coisa, minha mãe respondia que estava triste porque eu ainda não tinha nascido e já tinha saudades minhas.

- Como poderias ter saudade, se eu ainda não estava aqui? - eu perguntava. Eu sabia que ela sentia saudade de alguém que ela já perdeu, que a saudade é o efeito da perda.

- Mas também pode acontecer o contrário - ela me revidava. Se sentimos saudade de alguém, é porque está pessoa já está aqui.

Essas curtas conversas em alguma província do ocidente da Polônia durante o final dos anos sessenta, do século XX, entre minha mãe e eu, sua filha pequena, permaneceram na minha memória e me deram força por toda a minha vida. Pois, elevaram minha existência além da materialidade do mundo e do acaso, além das causas e efeitos, e as leis da probabilidade. Elas me deixaram um pouco além do tempo, numa doce proximidade com a eternidade. Entendi nos meus pensamentos de criança, que há mais vida do que eu havia imaginado. Inclusive vou exemplificar: "estou perdida", então por primeiro, encontre-se na frase: "eu sou" - a citação mais importante e intrigante do mundo.

Num contexto não religioso, minha mãe, me deu, o que antigamente se chamava espiritualidade, o que me proporcionou ser a melhor narradora do mundo.

2.

O mundo é um tecido que tecemos diariamente com os grandes teares de informações, debates, filmes, livros, fofocas e anedotas. Hoje, o alcance destes teares é enorme - graças a internet, quase todos podem participar deste processo assumindo suas responsabilidades ou não, com amor ou ódio, para o bem ou para o mal. Quando essa narrativa mudar também mudará o mundo. Neste sentido, o mundo é feito de palavras.

Assim, como conversamos sobre o mundo - o que parece ser mais importante - a narrativa passa a ter um significado importante, em relação a algo que acontece e deixa de ser dito, deixa de existir e morre. Sabem disso muito bem, não só os historiadores, mas também (e talvez sobretudo) toda a massa de políticos e tiranos. Esses que contam e governam a versão de uma narrativa histórica.

Hoje, ao que parece, o problema é que não temos narrativas prontas, não somente para o futuro, nem para o concreto "agora", nem sequer para as rápidas transformações do 
mundo de hoje. Falta-nos linguagem, pontos de vista, metáforas, mitos e novas fábulas. Entretanto, por isso somos espectadores desses dissimulados, que aproveitam das velhas narrativas enferrujadas e anacrônicas para desencorajar nossa visão sobre o futuro, presumindo que o velho é melhor do que a incerteza do novo, tentam lidar dessa forma, com as limitações dos nossos próprios horizontes. Resumindo, falta-nos novas formas de narrar a história do mundo.

Vivemos em meio a uma realidade polifônica de narrativas na primeira pessoa, e por isso estamos rodeados de ruídos barulhentos. O que quero dizer com a "primeira pessoa" são aquelas pessoas que não enxergam para além do seu umbigo, ficam somente no "eu", escrevendo somente sobre si e através de si mesmo. Reconhecemos, que este ponto de vista individualizado, esta voz de mim, é a mais natural, humana e honesta, inclusive das perspectivas mais amplas. Narrar em primeira pessoa é ter um padrão absolutamente único, ser um individuo com sentimento autônomo, ser consciente de si mesmo e do seu destino. Embora, isso possa também significar a construção de uma oposição entre mim e o mundo, e isso, às vezes, pode se tornar uma alienação.

Penso que a narrativa na primeira pessoa é uma característica da contemporaneidade em que o indivíduo desempenha o papel central da sua subjetividade no mundo. A civilização ocidental é formada em grande medida com base apenas na descoberta do "eu" como uma das medidas mais importantes. O ser humano é o principal ator e o seu julgamento - embora um entre muitos - será sempre tratado com atenção e seriedade. As narrativas tecidas na primeira pessoa parecem sempre estar entre as maiores descobertas da civilização humana, são lidas com reverência e plenas de confiança. Essa forma de narrar, quando vimos o mundo pelos olhos de algum "eu" e escutamos o mundo pelo seu nome, criamos um vínculo com o narrador sem igual, se colocando numa posição ímpar.

Não podemos negar o que as narrativas na primeira pessoa trouxeram para a literatura e em geral, para a civilização humana - reelaborou-se as histórias sobre o mundo, como lugar de heróis e divindades, as quais influenciaram nossa história individual e, portanto, proporcionaram espaço para pessoas como nós. Além disso, é mais fácil se identificar com pessoas que são como nós e graças a isso, nasce entre o narrador da história e os leitores ou ouvintes um vínculo emocional baseado na empatia. E assim, por conta da própria natureza, se aproximam e eliminam-se as fronteiras - é muito fácil estabelecer no romance os limites entre o eu-narrador e o eu-leitor. O romance, porém, pode abrir possibilidades de eliminar e anular essas fronteiras, graças a empatia dos 
leitores que com o tempo se convertem em narradores. A literatura, tornou-se, portanto, uma troca de experiencias, uma ágora onde todos podem contar sobre seus sonhos e dar voz ao seu alter ego. Portanto, é um espaço democrático, onde cada um pode falar ou criar uma voz que fale por si mesmo. Acho que nunca na história da humanidade tantas pessoas tornaram-se escritoras e narradoras. Basta olhar os dados estatísticos.

Quando vou às feiras de livros, vejo a quantidade de livros que são publicados mundialmente em que o personagem principal é o autor do livro. Por força da expressão, nosso instinto se projeta para proteger nossas vidas e se manifestar plenamente nas artes. Queremos que nos notem, queremos nos sentir excepcionais. Narrativas como, "vou te contar minha história", "vou te contar a história da minha família" ou eventualmente "vou te descrever, onde eu estive" são hoje as formas mais populares de literatura. Este é um fenômeno de grande escala, também porque hoje em dia, temos acesso universal aos escritos em que muitas pessoas são atraídas para esse meio, uma vez que são pessoas reservadas com pouca capacidade de se expressar por palavras as suas próprias narrativas. Paradoxalmente, no entanto, essa situação é similar a um coro composto somente por solistas, onde as vozes se sobrepõem para chamar a atenção, se movimentando por ondas semelhantes e eventualmente se interligando. Sabemos que todos poderão se identificar conosco e viver sua vida como se fosse a nossa. Ainda assim, é surpreendente, que muitos leitores fazem disso uma experiencia incompleta e decepcionante, porque a expressão autoritária do "eu" dificilmente garantirá a ideia de universalidade. Com isso, ao que parece, nos falta a parábola na dimensão da narrativa. Porque o herói da parábola é, ao mesmo tempo, um ser humano que cede em certas condições, especificamente históricas ou geográficas, ao mesmo tempo que vai para além dessa situação concreta se fazendo presente em qualquer lugar. Quando o leitor acompanha a história escrita em um romance pode identificar-se com a narrativa do personagem descrito e considerar essa situação como se fosse a sua, entretanto, deverá renunciar completamente a sua individualidade e permanecer na parábola. E na condição da parábola apelar para o lado psicológico, encontrando um denominador comum capaz de universalizar nossas experiências, apesar de muitas vezes, a parábola ser insuficiente e nos trazer desamparo.

Talvez para não nos afogarmos na multiplicidade de títulos e nomes, começamos a dividir o grande leviatã literário em gêneros, o qual tratamos como um campo de esportes, em que os escritores e escritoras são altamente treinados.

A comercialização geral do mercado literário levou a uma divisão de filiais passou a existir feiras e festivais deste ou daquele tipo de literatura, completamente 
divididos, criando uma clientela de leitores ansiosos por encontrar algum romance policial, uma fantasia ou ficção científica. Uma característica interessante dessa situação é que o que deveria ajudar os livreiros e bibliotecários a organizar suas prateleiras com a enorme quantidade de livros já publicados, e assim ajudar os leitores a se orientarem na vastidão de ofertas, passou a ser uma categoria abstrata, em que não apenas são feitos acréscimos às obras já lançadas, mas também os próprios escritores começaram a escrever sobre seus lançamentos. Cada vez mais, o trabalho deste gênero é como uma espécie de forma de bolo, onde se produz resultados muito parecidos, sua previsibilidade é considerada uma virtude, sua banalidade uma conquista. O leitor sabe o que esperar e consegue exatamente o que ele gostaria.

Intuitivamente, sempre me opus a essas ordens mercadológicas, porque elas provocam à limitação da liberdade autoral e a uma relutância em relação à experimentação e transgressão, o que é de fato a questão principal do criacionismo. Pois excluem completamente do processo criativo qualquer protagonismo, onde sem o qual não haverá arte. Um bom livro não precisa justificar sua filiação de gênero. A divisão em gêneros é resultante do mercado literário que tem como efeito o tratamento do produto para vender a toda filosofia branding, comercial e outras invenções similares do capitalismo contemporâneo.

Hoje, podemos ter a grande satisfação de ver o surgimento de uma maneira totalmente nova de contar a história do mundo por meio das séries de dramas, cuja intenção oculta é nos deixar em transe. É claro que esse modo de contar histórias já existia nos mitos e nos contos homéricos, Héracles, Aquiles ou Odisseu que são sem dúvida, os primeiros heróis das séries. Mas até então, essa forma nunca ocupou tanto espaço ou exerceu influência tão grande sobre a imaginação coletiva. As duas primeiras décadas do século XXI foram imprescindíveis para as séries. Sua influência nos modos de contar (e também de entender) o mundo foi revolucionária.

As séries, na versão de hoje, não apenas ampliaram nossa participação na narrativa sobre a esfera temporal, gerando vários ritmos, ramificações e aspectos, mas também introduziu suas próprias cronologias. Como em muitas situações, sua tarefa é prender a atenção do espectador pelo maior tempo possível - a narrativa da série multiplica os tópicos, entrelaçando-os da maneira mais improvável, tanto que quando se perde, volta a apelar às antigas técnicas de contar, antigamente comprometidas com a ópera clássica, “Deus ex machina". A criação de novos episódios geralmente envolve a total revisão psicológica dos personagens ad-hoc, para que eles se adaptem facilmente aos eventos 
desenvolvidos pelo enredo. Um personagem que começa como gentil e reservado termina vingativo e violento, um personagem secundário passa a ser o protagonista, enquanto o personagem principal que venerávamos perde seu significado ou até desaparece nos levando a consternação.

A possível continuação da próxima temporada cria a necessidade de finais abertos, nos quais ressoa o mistério da catarse de uma experiência anterior que não alterou o sentimento de satisfação na ação contada. Esse final aberto e não finalizado leva ao adiamento constante da recompensa que é a catarse - tornando o espectador dependente, hipnotizando-o. A fábula ininterrupta, criada há muito tempo, e bem conhecida pelas histórias de Scheherazade, retornou às séries em grande estilo, alterando nossa subjetividade provocando efeitos psicológicos bizarros, arrancando-nos das nossas próprias vidas e hipnotizando-nos como robôs. Ao mesmo tempo, a série se apresenta como nova, prolongando desordenadamente o ritmo do mundo, sua comunicação caótica, sua instabilidade e fluidez. Esta forma de contar histórias é provavelmente a mais criativa e hoje busca por novas fórmulas. Nesse sentido, há um trabalho sério nas séries sobre as narrativas do futuro, reformatando a história contada para que ela se adapte à nova realidade.

Mas, acima de tudo, vivemos em um mundo de fatos contraditórios e mutuamente exclusivos, todos lutando entre si com unhas e dentes.

Nossos ancestrais acreditavam que o acesso ao conhecimento não apenas traria felicidade, bem-estar, saúde e riqueza às pessoas, mas também criaria uma sociedade igual e justa. $\mathrm{O}$ que estava faltando no mundo, para eles, era a sabedoria onipresente que naturalmente surgiria da informação.

John Amos Comenius, o grande pedagogo do século XVII, cunhou o termo "pansofia", ao qual ele se referia à ideia de onisciência potente como um conhecimento universal que conteria toda a cognição possível. Era também, acima de tudo, um sonho do conhecimento acessível para todos. $\mathrm{O}$ acesso as informações sobre o mundo não transformariam um camponês analfabeto em um indivíduo reflexivo, consciente de si e do mundo? O conhecimento de fácil acesso não garante que as pessoas se tornarão sensatas e que direcionarão o progresso de suas vidas com serenidade e sabedoria?

Quando a Internet surgiu, parecia que finalmente essa ideia foi concretizada. A Wikipedia, que eu admiro e apoio, pode ser parecida a Comenius, como muitos pensadores que pensam de alguma forma, a realização de um sonho da humanidade - hoje podemos criar e receber uma enorme quantidade de informações que são incessantemente 
complementados e atualizados, disponíveis democraticamente a praticamente todos os lugares da Terra.

Um sonho realizado se trona muitas vezes decepcionante. Descobrimos que não somos capazes de suportar essa gama de informações, pois ao invés de unir, relativizar e libertar, elas se distanciam, são separadas e guardadas em pequenas gavetas, criando uma infinidade de histórias incompatíveis entre si ou até hostis, antagônicas.

Além disso, a Internet, total e irremediavelmente sujeita aos processos do mercado e dedicada aos articuladores do monopólio, controla quantidades gigantescas de dados, não sendo usadas como pansofia, em que possibilita um acesso mais amplo à informação, mas, pelo contrário, servindo sobretudo para programar o comportamento dos usuários como conhecemos o caso da Cambridge Analytica.

Ao invés de ouvir a harmonia do mundo, ouvimos uma cacofonia de sons, um zumbido insuportável no qual tentamos, desesperadamente, captar uma melodia mais calma, até uma batida mais leve. Shakespeare nunca foi tão adequado quanto para essa nova realidade cacofônica: cada vez mais a Internet é uma história, contada por um idiota, cheio de raiva e fúria.

Infelizmente, as pesquisas dos cientistas políticos também contradizem as intuições de John Amos Comenius, baseadas na ideia de que quanto mais universalmente fossem disponíveis as informações sobre o mundo, mais os políticos se valeriam delas para tomarem decisões acertadas. Parece que a questão não é tão simples assim. A informação pode ser esmagadora, em que sua complexidade e ambiguidade dão origem a todo tipo de mecanismo de defesa - da negação à repressão, até a perda dos princípios mais básicos de simplificar o pensamento, ideologicamente, partidariamente.

A categoria de fake news e fake up levanta novas questões sobre o que é ficção. Leitores que foram várias vezes enganados, desinformados ou alguém lhes passou a perna, começaram a adquirir lentamente uma específica idiossincrasia neurótica. A reação a tal exaustão com a ficção poderia representar o sucesso da não-ficção, que nesse grande caos informacional grita sobre nossas cabeças: "Vou lhe dizer a verdade, nada além da verdade" e "Minha verdade está baseada em fatos!".

A ficção perdeu a confiança dos leitores desde que a mentira se tornou uma arma perigosa de destruição em massa, mesmo que ainda seja uma ferramenta primitiva. Muitas vezes me fazem essa pergunta incrédula: “Isso que você escreveu é realmente verdade?” E toda vez sinto que essa pergunta é um presságio para o fim da literatura. 
Essa pergunta, inocente do ponto de vista do leitor, soa realmente apocalíptica para os ouvidos do escritor. O que eu devo falar? Como devo explicar o status ontológico de Hans Castorp, Anna Karenina ou Ursinho Pooh?

Acredito, em meio desse tipo de curiosidade do leitor, que a civilização está regredindo. É um prejuízo muito grande para nossa capacidade multidimensional (concreta, histórica, mas também simbólica e mítica) que compõem a cadeia de acontecimentos presentes nas nossas vidas. A vida é feita de eventos, mas somente quando somos capazes de interpretá-los, tentar entendê-los e dar um sentido, que eles serão transformados em experiências. Acontecimentos são fatos, mas a experiência é algo indiscutivelmente diferente. É a experiência, e não qualquer evento que compõe a matéria das nossas vidas. A experiência é um fato que foi interpretado e situado na memória. Também se refere a um certo fundamento que temos em nossas mentes, a uma estrutura profunda de significados sobre a qual podemos recriar nossas próprias vidas com um olhar atento e cuidadoso. Eu acredito que o mito desempenha a função dessa estrutura. Como todos sabem, o mito nunca aconteceu realmente, mas está ali sempre presente. Hoje, ele não estão apenas presente nas aventuras dos antigos heróis, mas também faz parte dos contos populares contemporâneos que encontramos nos filmes, nos jogos e na literatura. As vidas dos moradores do Monte Olimpo foram transferidas para a dinastia, e os atos heroicos passaram a ser interpretados por Lara Croft.

Nessa profunda divisão entre verdade e falsidade, os contos sobre a nossa experiência que a literatura cria têm suas próprias dimensões.

Nunca fiquei particularmente fascinada com qualquer distinção direta entre ficção e não-ficção, a menos que entendamos que essa distinção é declarada e necessária. Em um mar de definições sobre ficção, a que eu mais gosto é a mais antiga, vem de Aristóteles. A

\section{ficção é sempre um tipo de verdade.}

Também estou convencida cada vez mais das diferentes interpretações de enredos como aquele realizado pelo escritor e ensaísta Edward Morgan Forster. O romancista escreveu que, quando falamos: “O homem morreu e em seguida morreu a mulher", essa é uma relação. Mas quando mencionamos: "O homem morreu e em seguida a mulher morreu de tristeza", aqui temos uma ficção. Todo enredo provoca uma série de perguntas - “O que aconteceu depois?" é uma forma entendê-lo com base na nossa experiência humana: "Por que aconteceu dessa forma?"

A literatura parte de um "porquê", mesmo que tivéssemos como resposta rápida para pergunta tão simples: "não sei”. 
Assim, a literatura apresenta questões que não podem ser respondidas com a ajuda da Wikipedia, pois são questões que vão além de apenas fatos e informações, mas cavam diretamente nas nossas experiências pessoais.

No entanto, é visível que o conto e a literatura em geral estejam se tornando aos nossos olhos, algo realmente marginal em comparação com outras formas de contar a história. Com atenção a novos quadros usados para transmitir experiências - filme, fotografia, realidade virtual e augmented reality - constituirá uma nova alternativa ao leitor tradicional. A leitura é um processo psicológico e perceptivo bastante complicado. Simplificando: primeiro, o conteúdo mais esquivo é conceitualizado e verbalizado, transformando-se em sinais e símbolos, e em seguida é "decodificado" da linguagem para a experiência. Isso requer uma certa competência intelectual. Mas, acima de tudo, exige atenção e foco, habilidades cada vez mais raras num mundo extremamente perturbador.

A humanidade percorreu um longo caminho nas suas maneiras de se comunicar e compartilhar da experiência pessoal, da oralidade, contando com a história oral e a memória passando pela Revolução de Gutenberg, quando as histórias começaram a ser amplamente mediadas pela escrita e, dessa forma, preservadas e codificadas para ser reproduzida com o mínimo de alterações. A principal conquista dessa mudança foi que passamos a preservar a linguagem tal como é com a escrita. Hoje, claro, estamos enfrentando uma revolução em uma escala semelhante, quando a experiência pode ser transmitida diretamente, sem recorrer à palavra impressa.

Não há mais necessidade de fazer um diário de viagem quando você pode simplesmente tirar fotos e publicar nas redes sociais para todo mundo ver ou enviar a cada um. Não há necessidade de escrever cartas porque é mais fácil ligar. Por que escrever romances extensos, quando você pode simplesmente fazer uma série de televisão? Em vez de sair pela cidade para passear com os amigos, melhor é ficar jogando um jogo online. Ler uma autobiografia? Não faz sentido, já que estou acompanhando a vida das celebridades no Instagram e sei tudo sobre elas.

Hoje, nem sequer a imagem é o maior inimigo do texto, como pensávamos no século XX, quando nos preocupávamos com a influência da televisão e do cinema. Ao invés vez disso, há uma inversão completa do mundo - que age diretamente nas nossas formas de pensar.

3. 
Não quero esboçar uma crise geral ao relatar sobre as questões mundiais. Mas muitas vezes fico incomodada, com a sensação de que algo está faltando no mundo. A experiencia pela tela ou aplicativo, se torna de alguma forma não real, distante, multidimensional e indefinida, mesmo que acessar qualquer informação, em particular, é surpreendentemente fácil. Questões como, "quem", “o que”, “onde" e "quando" podem ser hoje mais perigosas do que a simples divulgação daquelas ideias distorcidas e anunciadas com bastante certeza como "a terra é plana", "as vacinas matam", "as mudanças climáticas não fazem sentido" ou "a democracia em muitos países não está sendo ameaçada". "Em algum lugar" pessoas estão se afogando enquanto tentam atravessar o mar. "Em algum lugar", por "algum” tempo, "algum tipo de" guerra está acontecendo. O fluxo de informações individuais perde seu contexto, e ganha dimensão em nossas memórias descontextualizadas e não reais.

A inundação de estupidez, crueldade, discurso de ódio e imagens de violência são desesperadamente contrabalançadas com todos os tipos de "boas notícias", mas que não tem a capacidade de conter a impressão dolorosa e difícil de verbalizar, de que não é realmente assim - há algo errado com o mundo. Esse sentimento, reservado unicamente aos poetas neuróticos, está se tornando hoje uma epidemia sem definição, permeado de ansiedade por todos os lados.

A literatura é uma das poucas esferas que nos tenta manter próximos do mundo concreto, porque a sua própria natureza, é sempre "psicológica", porque se concentra no raciocínio interno e nas causas dos personagens que revelam sua experiência inacessível a outras pessoas ou, simplesmente atenta o leitor a uma interpretação psicológica da sua conduta. Somente a literatura é capaz de nos aproximar com mais profundidade da vida do outro, entender suas razões, compartilhar suas emoções e vivenciar seu destino.

A crônica sempre circula em torno do significado. Mesmo que não o expresse diretamente, mesmo quando se recusa deliberadamente a buscar significado, e se concentra na forma, no experimento, encenando uma rebelião formal, procurando novos meios de expressão. Mesmo quando lemos o conto escrito de forma mais comportamentalista e moderada, não podemos deixar de fazer perguntas: "Por que isso está acontecendo?”, “O que isso significa?”, “Qual é o objetivo disso?”, “Aonde isso vai chegar?” Muito provavelmente, nossas mentes evoluíram na direção das narrativas como um processo de dar sentido a milhões de estímulos que nos cercam, e que mesmo quando dormimos, continuamos ideando incansavelmente suas histórias. Portanto, a narrativa é uma maneira de organizar uma quantidade infinita de informações no tempo, 
estabelecendo sua relação com o passado, o presente e o futuro, revelando sua recorrência e organizando-o em categorias de causa e efeito. Tanto o pensamento quanto as emoções participam desse esforço.

Não é de se admirar que uma das primeiras descobertas feitas pelas crônicas tenha sido o Destino, que além de sempre parecer às pessoas como algo aterrorizante e desumano, de fato introduziu ordem e imutabilidade na realidade cotidiana.

4.

Senhoras e Senhores,

A mulher da fotografia, minha mãe, que sentia minha falta, embora eu ainda não tivesse nascido, anos mais tarde, estava lendo para mim contos de fadas.

Em um deles, de autoria de Hans Christian Andersen, um bule que havia sido jogado na lixeira, reclamou da crueldade com que fora tratado pelas pessoas - se desfizeram dele, assim que sua alça quebrou. Mas se as pessoas não fossem tão perfeccionistas e exigentes, ainda poderia ter sido útil para elas. Outros objetos quebrados recorreram a essa melodia e contaram histórias verdadeiramente épicas de suas pequenas e modestas vidas de objetos.

Quando criança, eu ouvia esses contos de fadas com as bochechas coradas e lágrimas nos olhos, porque acreditava profundamente que os objetos tinham seus próprios problemas, seus sentimentos e também um tipo de vida social comparável à nossa vida humana. Os pratos na prateleira podiam conversar entre si, e as colheres, facas e garfos na gaveta formavam uma espécie de família. Da mesma forma, os animais eram criaturas misteriosas, sábias e autoconscientes, com quem sempre tínhamos sido conectados por um vínculo espiritual e uma profunda semelhança. Os rios, as florestas e as estradas também tinham sua existência - eram seres vivos que mapearam nosso espaço e criaram um sentimento de pertencimento, um misterioso Raumgeist. A paisagem que nos cercava também estava viva, assim como o Sol e a Lua, e todos os corpos celestes - tudo aquilo que é visível e invisível.

Quando começo a duvidar disso? Procuro encontrar algum momento da minha vida em que, ao apertar um botão, tudo se torna diferente, menos colorido, mais simplificado. O sussurro do mundo silenciado é substituído pelo estalo das cidades, pelo chiado dos computadores, pelo trovão dos aviões voando no céu e pelo ruído branco e exaustivo dos oceanos de informações. 
Em algum momento das nossas vidas, começamos a ver o mundo fragmentado, tudo separado, em pedaços distanciados entre si como galáxias diante da realidade da terra que nos firma. Os médicos nos tratam pelas especialidades, os impostos não têm relação com a retirada da neve nas estradas pela qual passamos para ir ao trabalho, nosso almoço não tem nada a ver com uma grande granja de gado, ou a fabricação de uma nova blusa em algum lugar precarizado da Ásia. Tudo é separado entre si, vivem à parte, sem explicitar conexões.

Para isso ficar mais claro para nós, recebemos números, crachás, cartões, blocos de identidades plásticas que tentam nos reduzir ao uso de uma pequena parte do todo o resto que já deixamos de ver.

O mundo está morrendo e nós nem estamos percebendo. Não vemos que o mundo está se tornando uma coleção de coisas e incidentes, morto e sem sentido, no qual nos movemos perdidos e solitários, varridos pelas decisões de alguém, limitados por um destino incompreensível, uma sensação de ser o brinquedo das principais forças da história e do acaso. Nossa espiritualidade está desaparecendo ou se tornando superficial e ritualística. Ou apenas nos tornamos seguidores das forças simples - físicas, sociais e econômicas - as quais nos movem como se fôssemos zumbis. E nesse mundo, somos realmente zumbis. É por isso que sinto falta daquele mundo do bule.

5.

Toda a minha vida fiquei fascinada pelos sistemas de conexões e influências mútuas que geralmente desconhecemos, mas que descobrimos por acaso, com surpreendentes coincidências ou convergências do destino, todas aquelas pontes, porcas, parafusos, juntas soldadas e conectores que eu usei em Biegunach ${ }^{i v}$. Fico fascinada por associar fatos e por me orientar por ordenações. Basicamente, estou convencida de que a mente do escritor é uma mente sintética que reúne obstinadamente todas as pequenas peças, na tentativa de juntá-las para criar novamente um todo universal.

Como devemos escrever, como devemos estruturar nossa narrativa para ser capaz de elevar essa grande forma de constelação do mundo?

Naturalmente, percebo que não é possível retornar ao tipo de narrativa sobre o mundo que conhecemos dos mitos, fábulas e lendas que, ao ser repassada de boca em boca mantinha o mundo vivo. Hoje em dia essa forma de contar teria que ser muito mais multidimensional e complexa. Afinal, sabemos realmente muito mais, estamos cientes das incríveis conexões entre as coisas que aparentemente parecem distantes. 
Vamos dar uma olhada em um dado momento particular da História do Mundo.

Em 3 de agosto de 1492, o dia em que uma pequena caravela chamada Santa Maria zarpou de um cais no porto de Palos, na Espanha. O navio é comandado por Cristovão Colombo. O sol brilha, há marinheiros indo e vindo no cais e estivadores carregando as últimas caixas de provisões a bordo. Faz calor, mas há uma brisa leve vinda do Oeste e salva as famílias que vieram se despedir do fracasso. Gaivotas sobrevoam ligeiramente para cima e para baixo a rampa de carregamento, observando de perto as atividades humanas.

O momento que agora podemos imaginar, levou ao longo do tempo, à morte de 56 milhões dos quase 60 milhões nativos americanos. Na época, eles representavam cerca de $10 \%$ de toda a população do mundo. Os europeus inconscientemente lhes trouxeram alguns presentes letais - doenças e bactérias às quais os habitantes indígenas da América não tinham resistência. Além disso, veio a opressão e a morte. O extermínio continuou por anos e mudou a natureza da terra. Lá onde antes crescia feijão e milho, batatas e tomates em campos irrigados, cultivados de maneira sofisticada, a vegetação selvagem retornou. Em apenas alguns anos, quase 60 milhões de hectares de terra arável transformaram-se em selva.

À medida que se regenerava, a vegetação consumia grandes quantidades de dióxido de carbono, enfraquecendo o efeito estufa. E assim diminuía a temperatura global da Terra.

Essa é uma das muitas hipóteses científicas para explicar o início da Pequena Era Glacial na Europa, no final do século XVI, que provocou um resfriamento a longo prazo do clima.

A Pequena Era Glacial mudou a economia da Europa. Ao longo das décadas que se seguiram, os longos invernos congelantes, os verões frios e a intensa precipitação reduziram o rendimento das formas tradicionais de agricultura. Na Europa Ocidental, pequenas fazendas familiares que produziam alimentos para suas próprias necessidades se mostraram ineficientes. Seguiram-se ondas de fome e houve a necessidade de especializar a produção. Inglaterra e Holanda foram os países mais afetadas pelo clima mais frio; como suas economias não podiam mais depender da agricultura, começaram a desenvolver o comércio e a indústria. A ameaça de tempestades levou os holandeses a secar os poços e converter banhados e áreas banhadas pelas zonas costeiras em terras cultiváveis. A mudança para o Sul da faixa onde se produzia bacalhau, embora tenha sido catastrófico para a Escandinávia, provou ser vantajosa para a Inglaterra e Holanda - graças a isso, 
esses países começaram a se transformar em potências navais e comerciais. $\mathrm{O}$ resfriamento significativo foi sentido particularmente em alguns países escandinavos. $\mathrm{O}$ contato com a Groenlândia e a Islândia foi interrompido, os invernos severos reduziram as colheitas e surgiram anos de fome e escassez. Então a Suécia voltou seu olhar ganancioso para o Sul, embarcando numa guerra contra a Polônia (justamente porque o Mar Báltico havia congelado, facilitando um exército marchar por ele) e assim se envolver na Guerra dos Trinta Anos da Europa.

Os esforços dos cientistas, tentando estabelecer uma melhor compreensão da nossa realidade, mostram que é um sistema de influências mutuamente coerente e densamente conectado. Isso não é mais apenas o famoso "efeito borboleta", que como sabemos, envolve o modo como mudanças mínimas no início de um processo podem levar no futuro a resultados tremendos e imprevisíveis. Mas, aqui temos um número infinito de borboletas e suas asas, em constante movimento - uma poderosa onda de vida que viaja pelo tempo.

Na minha opinião, a descoberta do "efeito borboleta" marca o fim da era da fé inabalável em nossa própria capacidade de ser eficaz, nossa capacidade de controlar e, da mesma forma, nosso senso de supremacia no mundo. Isso não tira da humanidade nosso poder de ser um construtor, um conquistador e um inventor, mas mostra que a realidade é mais complicada do que a humanidade jamais poderia ter imaginado. E que nós não somos nada mais do que uma pequena parte desse processo.

Temos cada vez mais evidência de existências espetaculares, às vezes altamente surpreendentes, relacionadas em escala mundial.

Somos todos - nós, plantas animais, objetos - imersos em um único espaço, que é regido pelas leis da física. Esse espaço comum tem sua forma e, dentro dele, as leis da física esculpem um número infinito de formas que são incessantemente ligadas umas às outras. Nosso sistema circulatório é como o sistema de uma bacia hidrográfica, a estrutura de uma folha é como um sistema de comunicação humana, o movimento das galáxias como o turbilhão de água que flui nos nossos lavatórios. As sociedades se desenvolvem de maneira semelhante às colônias de bactérias. As escalas micro e macro mostram um sistema interminável de similaridades. Nossos discursos, pensamentos e criatividades não são algo abstrato, desprovido do mundo, mas uma continuação em outro nível de seus processos intermináveis de transformação.

6. 
O tempo inteiro fico me perguntando, se atualmente é possível encontrar os fundamentos de uma nova narrativa universal, abrangente, absoluta, arraigada na natureza, contextualizada e ao mesmo tempo comprometida.

Haveria uma narrativa que iria além das grades da não comunicação do próprio “eu”, revelando uma maior variedade da realidade e apontando para as conexões mútuas? Seria possível manter distância da banalidade de um ponto central e óbvio "uma visão amplamente compartilhada" e tentar olhar as coisas ex-cêntricas, longe do centro?

Fico feliz ao saber que a literatura tenha mantido maravilhosamente bem o direito a todo tipo de excentricidade, fantasmagoria, provocação, paródia e loucura. Sonho com altos pontos de vista e amplas perspectivas, em que o contexto vai muito além do que poderíamos esperar. Sonho com uma linguagem capaz de expressar a mais vaga intuição, sonho com uma metáfora que supera as diferenças culturais e, finalmente, com um gênero que será amplo e transgressivo, ao mesmo tempo em que os leitores se apaixonarão por ele.

Também sonho com um novo tipo de narrador - o da "quarta pessoa", o qual não apenas está relacionado a uma construção gramatical, mas que consegue abranger para si a perspectiva de cada um dos personagens, além de ter a capacidade de ir além do horizonte de cada um deles, que vê para além, tem uma visão mais ampla, e que é capaz de ignorar o tempo. Ah, sim, a existência desse narrador é possível.

Você já se perguntou alguma vez, quem é o maravilhoso contador das histórias da bíblia que fala em voz alta: "No princípio era a palavra"? Quem é que descreve sobre a criação do mundo, seu primeiro dia, quando o caos foi separado da ordem? Quem segue a série sobre a origem do Universo? Quem conhece os pensamentos de Deus, conhece suas dúvidas e com a mão firme escreve no papel a frase incrível: "E Deus reconheceu que isso era bom"? Quem é esse, quem sabia o que Deus pensava?

Deixando de lado todas as dúvidas teológicas, podemos considerar esta figura de um narrador misterioso e terno como maravilhosa e significativa. Este é um ponto de vista, uma perspectiva, de onde podemos ver tudo. Ver tudo significa reconhecer ao final o fato de que todas as coisas que existem estão mutuamente conectadas num único ponto, mesmo que as conexões entre elas ainda sejam desconhecidas de nós. Ver tudo também significa um tipo completamente diferente de responsabilidade pelo mundo, porque fica óbvio que todo gesto "aqui" está conectado com o gesto "lá", que uma decisão tomada em uma parte do mundo terá efeito em outra parte, e a diferenciação entre "meu" e "seu" passa a ser discutível. 
Portanto, seria mais honesto, contar histórias de uma maneira que ativasse todo o sentido na mente do leitor, oportunizando a capacidade do leitor unir os fragmentos em um único ponto, por meio da descoberta de pequenas partículas em meio as constelações. Contar uma história de forma que evidencie que tudo e todos estão imersos em um plano comum, que são produzidas minuciosamente em nossas mentes, a cada volta que o planeta dá.

A literatura tem esse poder. Deveríamos descartar a categoria simplista da literatura de alto e baixo nível, popular e de nicho, e considerar a divisão dos gêneros literários menos acentuada. Eliminar a definição de "literaturas nacionais", sabendo que o universo da literatura é uma coisa única, como a ideia de unus mundus, uma realidade psicológica comum na qual nossa experiência humana está unida, em que o Autor e o Leitor desempenham papéis equivalentes, o primeiro porque se empenha na criação, e o segundo, graças a isso, pode prosseguir com suas interpretações.

Talvez devêssemos confiar mais nos fragmentos, pois são os fragmentos que criam constelações capazes de escrever mais, de uma maneira mais complexa, multidimensional. Nossas narrativas poderiam estar relacionadas entre si de uma maneira infinita, em que seus personagens centrais poderiam conversar.

Penso que temos que redefinir isso, o que entendemos hoje sobre o conceito de realismo, e buscar por algo novo, capaz de ir além das fronteiras do nosso ego e penetrar a tela de vidro pela qual vemos o mundo. Porque as reais necessidades de hoje são atendidas pela mídia, pelos portais sociais e pelas relações indiretas na internet. Talvez, o que nos aguarda daqui pra frente, seja uma espécie de neo-surrealismo, alguns pontos de vista reorganizados que não terão medo de resistir a um paradoxo e irão contracorrente daquilo que se trata de uma ordem simples de causa-e-efeito. De fato, nossa realidade já se tornou surreal. Também tenho certeza de que muitas narrativas exigem reescrita nos nossos novos contextos intelectuais, inspirando-se nas novas teorias científicas. Mas acho igualmente importante fazer referência constante aos mitos e a todo o imaginário humano. Retornar às estruturas compactas da mitologia poderá nos trazer uma sensação de estabilidade ante a falta de especificidade em que estamos vivendo atualmente. Acredito que os mitos são o material de construção de nossa psique, e não podemos ignorá-los (no máximo, podemos desconhecer sua influência).

Sem dúvida, um gênio deverá aparecer em breve, que poderá elaborar uma narrativa totalmente diferente, ainda inimaginável, na qual tudo o que for necessário se acomodará. Esse método de contar histórias certamente nos mudará; abandonaremos 
nossas restritas e velhas perspectivas e nos abriremos para novas que sempre existiram em algum lugar aqui, mas estávamos cegos delas.

Em Doutor Faustus, Thomas Mann escreveu sobre um compositor que inventou uma nova forma de música absolutamente capaz de mudar o pensamento humano. Mas Mann não descreveu como essa música deveria acontecer, ele apenas criou a ideia imaginária de como isso poderia soar. Talvez seja nisso que se embasa o papel de um artista: dar uma amostra de que poderia existir e, assim, fazer com que se torne imaginável. Ser imaginado é o primeiro estágio da existência.

7.

Eu escrevo ficção, mas isso nunca é algo tirado da cartola. Quando escrevo, tenho que sentir tudo dentro de mim. Eu tenho que deixar todos os seres vivos e objetos que aparecem no livro passarem por mim, tudo o que é humano e além do humano, tudo o que é vivo e o que não é dotado de vida. Eu tenho que olhar de perto cada objeto e pessoa, com a maior solenidade, e personificá-las dentro de mim, personalizá-los.

É para isso que serve o sensível - porque a sensibilidade é a arte de personificar, compartilhar sentimentos e, assim, descobrir semelhanças. Criar narrativas significa dar vida às coisas constantemente, dando existência a todos os pequenos pedaços do mundo que são representados pelas experiências humanas, as situações que as pessoas sobrevivem e suas memórias. A sensibilidade personaliza tudo a que se relaciona, tornando possível dar voz a ela, dar espaço e tempo para que ela exista e seja expressa. É graças a ela que o bule começa a falar.

A sensibilidade é a forma mais modesta de ternura. É o tipo de ternura que não aparece nas escrituras ou nos evangelhos, ninguém se compromete com ela, ninguém as referencia. Não tem seus emblemas nem símbolos, não leva ao crime ou a inveja imediata.

Surge lá, onde prestamos atenção, focando o outro com cuidado, naquilo, que não sou "eu".

A ternura é espontânea e desinteressada; vai muito além da empatia e compaixão. É um compartilhamento consciente, embora talvez um pouco melancólico, da partilha do destino. A ternura é uma profunda preocupação emocional com o outro, sua fragilidade, sua natureza única e sua falta de resistência aos sofrimentos e aos efeitos do tempo. 
A ternura sensível identifica os laços que nos conectam, as semelhanças e as mesmidades entre nós. É uma forma de olhar que mostra o mundo vivo, vivido, interconectado, cooperando e pertencente a si mesmo.

A literatura é construída sobre uma ternura sensível em relação a qualquer um que não sejamos nós mesmos. É o mecanismo psicológico básico do romance. Graças a essa ferramenta milagrosa, o meio mais sofisticado da comunicação humana, nossa experiência pode viajar pelo tempo chegando naqueles que ainda não nasceram, mas que um dia recorrerão ao que escrevemos, as narrativas que contamos sobre nós mesmos e nosso mundo.

Não tenho ideia de como será a vida deles ou quem serão. Constantemente penso neles com culpa e vergonha.

A emergência climática e a crise política na qual estamos tentando encontrar o nosso caminho, e à qual estamos resistindo ansiosamente para salvar o mundo, não surgiram do nada. Muitas vezes esquecemos que não são apenas fatos e peculiaridades do destino, mas resultados bastante concretos de alguns movimentos e decisões muito específicas - econômicos, sociais e aquelas relacionadas às perspectivas de mundo (incluindo as religiosas). Ganância, falta de respeito à natureza, egoísmo, falta de imaginação, rivalidade sem fim e falta de responsabilidade reduziram o mundo ao status de um objeto que pode ser partido em pedaços, usado e destruído.

Por isso, acredito que devo escrever como se o mundo fosse uma entidade viva e única, se formando constantemente diante dos nossos olhos, e como se nós fôssemos ele - uma pequena potência - uma partícula.

Submetido em: 03/06/2020

Aprovado em: 22/06/2020

Publicado: 23/09/2020

\footnotetext{
${ }^{\text {i }}$ Ensaio apresentado pela escritora polonesa Olga Tokarczuk ao receber o Prêmio Nobel de Literatura, em 7 de dezembro de 2019, em Estocolmo/Suécia. O texto original está disponível em: Olga Tokarczuk - Nobel Lecture. NobelPrize.org. Nobel Media AB 2020. Tue. 2 Jun 2020. <https://www.nobelprize.org/prizes/literature/2018/tokarczuk/lecture/>

ii Pela quinta vez, a Polônia foi laureada com o Prêmio Nobel de Literatura. Desta vez se trata da escritora mulher Olga Tokarczuk, (a primeira foi a poeta Wislawa Szymborska, em 1996) e a 15 a mulher na história do prêmio. Um viva as mulheres! [Notas da tradutora]
} 
iii Doutora em História da Educação pela UFSC. Realizou Pós-Doutorado na Universidade de Varsóvia. iv Título original da obra laureada pelo Nobel, traduzido em inglês para "Flights" por Jennifer Croft e do inglês para espanhol para "Los Errantes". 